\title{
Digital Design for Sustainable Behaviour: A conceptual framework to guide design intervention.
}

\author{
Marcus Hanratty, \\ Loughborough Design School, \\ Loughborough University, \\ LE11 3TU, \\ E-Mail: m.hanratty@lboro.ac.uk
}

\author{
Tracy Bhamra, \\ Loughborough Design School, \\ Loughborough University, \\ LE11 3TU, \\ E-Mail: T.Bhamra@lboro.ac.uk
}

\author{
Val Mitchell, \\ Loughborough Design School, \\ Loughborough University, \\ LE113TU, \\ E-Mail: v.a.mitchell@lboro.ac.uk
}

\begin{abstract}
Domestic energy consumption is increasing in the UK's housing stock in the face of government commitments to reduce $\mathrm{CO}_{2}$. Occupant behaviour has been targeted as a promising area in which to effect a reduction in consumption levels but has proved resilient to high level intervention approaches. This short paper explores the constituent elements of energy consuming behaviour and habits and puts forward a conceptual framework to guide future design intervention. Central to this is the implementation of Design for Sustainable Behaviour methodologies to change the nature of occupant-appliance interaction. The paper concludes with a discussion of the role of Digital Media as an agent for such behavioural change.
\end{abstract}

Behaviour, Habits, Design for Sustainable Behaviour, Domestic Energy Consumption, Digital Media.

\section{INTRODUCTION}

The UK has targeted an $80 \%$ reduction on 1990 levels of greenhouse gas (GHG) emissions by 2050. In order to meet this deadline, levels of domestic energy use must be reduced to a far more sustainable level. Domestic energy use was responsible for $31 \%$ of UK energy use in 2010 (DECC 2011). Energy use in the domestic sphere has continued to rise, even in the face of a continued reduction in national energy use over the last 20 years. While there has been a steady increase in the energy efficiency of domestic technologies, this has been offset by increasing consumption (Druckman, Chitnis et al. 2011).

Changing occupant behaviour is considered to be a fruitful area for energy reduction (Phillips and Rowley 2011), a finding which is backed up by studies showing that occupant behaviour alone can affect domestic energy use by a factor of two in identical houses inhabited by similar families (Gill, Tierney et al. 2010). However, domestic energy consuming behaviour is often contingent on the interplay of a large number of factors and clearer understanding of these factors is needed to guide the development of suitable intervention strategies.

\section{RESEARCH BACKGROUND}

The research described here takes place within the context of the EPSRC funded LEEDR project (Low Effort Energy Demand Reduction, 2010-2014).
LEEDR is a multidisciplinary project based in Loughborough University and brings together researchers from the several departments. LEEDR has recruited 20 families in the East Midlands for a three year period to engage in high-definition energy consumption monitoring and in-depth behavioural and contextual inquiry. The project has a particular focus on the role of digital media in domestic energy consumption, as a net consumer of energy and particularly as a potential platform for energy demand reducing interventions.

In this context, this paper will outline the elements of occupant behaviour as used to create a framework for designing behaviour changing interventions. This framework is an intentionally broad overview with the aim of being flexible enough to allow design interpretation in disparate areas. In addition, this paper will also examine the potential role of Digital Media (DM) as an agent of behavioural change in domestic energy consumption.

\section{CONCEPTUAL FRAMEWORK}

In order to change behaviour, it must first be understood at a constituent level. A literature review of behaviour models and theory, design intervention strategy, and design for sustainable behaviour methodologies was drawn together to create a conceptual framework to aid the design process. This is not a new behavioural model, but rather an extrapolation of the literature into a more 
workable, designerly form. There are two main elements to the framework; the first illustrates the constituents of behaviour and the nature of habit formation, the second outlines the means that can be employed to design behaviour changing interventions and their potential effect on the constituents of a given behaviour. The framework is not considered to be exhaustive nor definitive (the multitudinous variables and possible approaches to behaviour change make that impossible), but is aimed at providing a clear overview of the problem space.

\subsection{Context/Behaviour/Habits}

All behaviour occurs in given physical and societal context comprised of people, place, and things (Stern 1999) and is shaped by the constraints and affordances thereof (Norman 1990). Within their context each user is considered to have their own practical knowledge, attitudes, and beliefs which shape their worldview and are unique to the individual. These qualities interface with context to determine the scope of the behaviour possible, but the nature of the context also plays a dynamic role in mediating and moderating the individuals motivation to act in certain way (Steg and Vlek 2009). The nature of the context, and any technologies it may contain, frame the percieved behavioural possibilities which in turn shape the motivational domain.

As a tool to understanding behavioural motivation, Lindenberg and Steg (2007) propose Goal Framing Theory, which states that in a given context, the decisions people make, particularly in the early phase of a behaviour, are driven by a combination of three goal frames; Hedonic - to feel better now, Gain - to guard or improve one's resources, Normative - to act appropriately. In every decision all three goal frames are present but one (or two) will be dominant. As an example imagine while lying in bed on a cold winters night you remember you left on the lights in the study downstairs and think to yourself; "I know I should go downstairs and turn them off because it is a waste of money, but I'm so comfortable in bed right now". In this case the hedonic goal frame as mediated by the context dominates both the intention to act appropriately and to guard ones resources. In each instance the active motivational goal "frames" the information and values the individual draws on to support the behaviour. As such environmental or normative information is unlikely to trigger appropriate action when the active goal frame is hedonic or gain based unless it can be appropriately inserted into the behavioural context at the right time.

This selective situational goal framing goes some way towards explaining the attitude-behaviour gap often encountered by those trying to effect environmental behavioural change, and understanding of it is central to the design of behaviour changing interventions. The other element crucial for intervention is the nature of the context the behaviour occurs in. In the example above it is the effort and discomfort of having to physically move through a cold house and switch off the lights which makes the action incompatible with the dominant goal frame. While changing that goal frame through persuasive means is possible (e.g. Cialdini 2001), perhaps more fruitful is changing the nature of the context through design intervention. The provision of a bedside switch or a smart phone app which allowed remote control of the lights would entirely change the nature of the interaction required and place it line with any dominant goal frame. By contrast, if such a smart phone app just provided persuasive information, the likelihood of user compliance would be much lower as the effort would remain the same.

This ability to design "new" behavioural contexts though product and interaction design becomes even more pertinent in the domain of habitual behaviour. When a behaviour is regularly repeated and the context remains the same, then it will become more automatic and require less and less cognitive deliberation (Verplanken and Aarts 1999). The behaviour can become habitual and thus initiated by contextual cues and performed outside of the user's conscious awareness. Much energy related behaviour is habitual in nature and is often built into context dependent routines (Martiskainen and Coburn 2010), indeed one study estimates that $45 \%$ of our daily actions are habitual in nature (Verplanken and Wood 2006). In this form a habit can perpetuate and strengthen until there is a change in the context or a conscious change in the user's knowledge, attitudes and beliefs. However, it is extremely difficult to effect conscious change to habits as they are contextually cued and performed unconsciously. Thus, changing the nature of the behavioural context can be more effective as those cues can be removed or the nature of the interaction required changed and the behaviour brought back to the declarative stage. Nonetheless, total context change is rarely an option, and the designer must balance technical and financial feasibility against user acceptance and autonomy when creating interventions.

\subsection{Design for Sustainable Behaviour}

In terms of domestic energy use, which is often determined by behaviour (Bhamra, Lilley et al. 2008), both our homes themselves and the products and appliances within all set forth a range of overt or tacit scripted (Jelsma and Knot 2002) interactions which strongly shape the manner in 


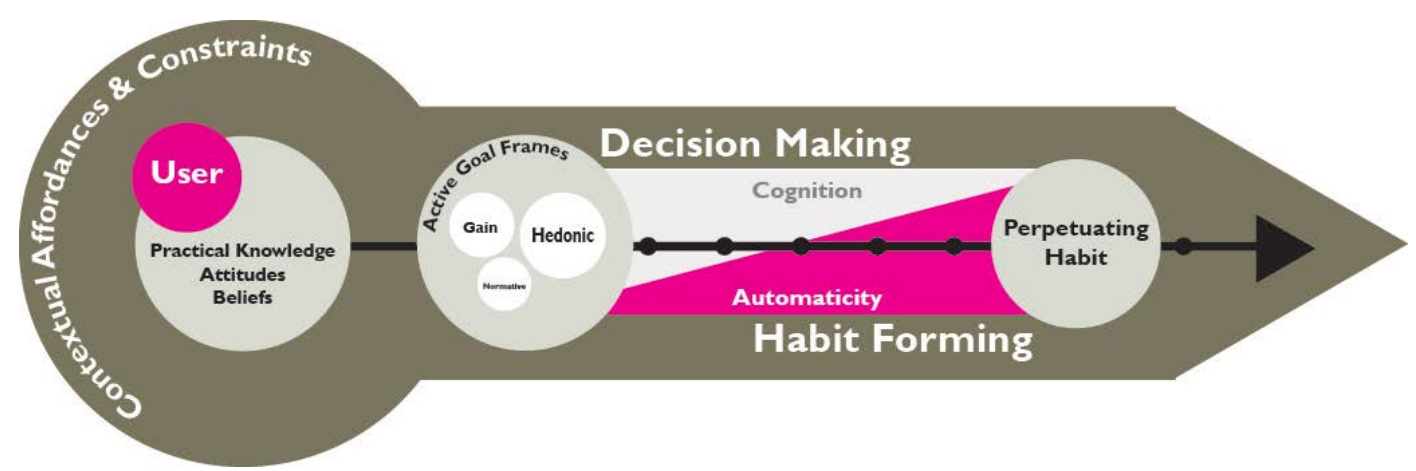

Figure 1: Constituents of Behaviour and Habit Formation

which we do or don't use them. Lilley (2009) argues that there is an axis of influence in the interface of user and product that determines where the decision making power lies. This runs between two poles, one end is User Agentive where the user has the power and ability to use the product in whatever way they wish. The other pole is Technological Agentive where the product's form and/or functional capabilities donate the mode of use entirely. Recognising this axis of influence allows the designer to position an intervention in a manner which best balances the needs and goals of the user with the nature of the targeted behaviour. Zachrisson and Boks (2010) positioned intervention strategies in relation to this user/technology axis of control in ascending strength (Figure 2).

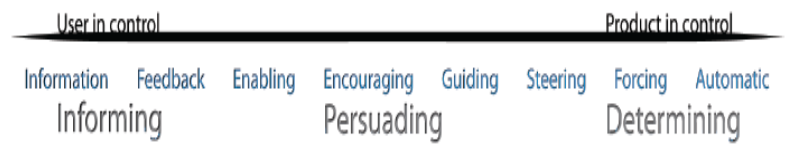

Figure 2: User/Product Axis of Control (Zachrisson and Boks 2010)

Interventions with the user in control generally seek a considered response from the individual to change their behaviour. Whereas those towards the technology being in control end of the axis tend to reduce the ability of the user to perform the behaviour at all or remove its negative impact through technological efficiency. All interventions are to some extent changes to the context, but those which force a change in the behavioural interaction (even while maintaining autonomy and choice) have a greater chance of success.

These Design for Sustainable Behaviour (DfSB) methodologies represent a potentially powerful set of environmental behaviour change strategies, however their effect can only be realised if the various intervention approaches are correctly matched to the users' needs, knowledge and motivations. This implies that a Human Centred Design (HCD) approach should be taken to uncover users' needs, to understand behaviours and the physical and societal context in which their actions take place (Wilson, Bhamra et al. 2010). To prevent a misinterpretation of the users' goals and motivations Midden, Kaiser et al. (2007) advocate user trialling and prototyping of different levels of interventions and functionalities to determine the optimum solution.

\subsection{The Role of Digital Media in Behaviour Change}

When combined with an appropriate DfSB strategy, DM (particularly in the form of portable media devices like smartphones, laptops etc.) can be a powerful platform for design intervention. DM can provide a vehicle for a change in the behavioural context or in the user's knowledge, attitudes and beliefs (Fogg, 2003). It can reshape the user's physical context by providing remote sensing, connectivity and remote control, enabling them to act on a new virtual stage unencumbered by existing contextual cues. It can also reshape the societal context by linking people from different areas and backgrounds to create new communities and norms. Simultaneously, the DM intervention becomes part of the user's context itself, and can have appropriate constraints and affordances designed into it to steer and force behaviour in a particular direction.

By thus changing the context, digital DfSB interventions can potentially break the hold of the user's existing context on their habitual behaviour and bring the behaviour back to the declarative stage. At this point the full gambit of DfSB strategies can be brought into play to give the user new knowledge, and to shift their attitudes and beliefs towards more environmentally beneficial ones. If successful, when the user embarks upon the new behaviour, different factors will affect the active goal frames, leading to a more sustainable choice. While it might be expected that environmentally beneficial behaviour would be driven by revised active normative goal frames, in actuality it would depend on the interplay of the designed affordances and constraints of the system and the nature of the user's new knowledge, attitudes and beliefs. 
Key in this process is the selection of a combination of an appropriate DfSB strategy(s) and the requisite contextual change. To this end the user's active goal frames must be understood and the nature and degree of habit formation ascertained. The goal frames can be revealed through targeted interviews and participatory design activities incorporated into the HCD process. Adoption of a participatory process also ensures ethical suitability.

\section{REFLECTIONS AND FUTURE DIRECTIONS}

While this paper has only allowed a brief overview of this conceptual framework, it is hoped it has provided some insight into its basic premise of exposing the relationships between some of the key elements in occupant behaviours, and a means of addressing them through digital design. The framework has been used to guide the design investigation in the LEEDR project and has helped uncover a rich picture of context mediated motivations, behaviours and habits.

\section{ACKNOWLEDGMENTS}

The interdisciplinary LEEDR project, based at Loughborough University, is jointly funded by the UK Research Councils" Digital Economy and Energy programmes (grant number EP/I000267/1). For further information about the project, collaborating research groups and industrial partners, please visit www.leedrproject.co.uk. The author would like to thank all the households who have generously participated in this research.

\section{REFERENCES}

Bhamra, T., D. Lilley, et al. (2008). Sustainible Use: Changing consumer behaviour through product design. Changing the Change, Turin, Italy, 1012 July 2008

Cialdini, R. B. (2001). Influence: Science and practice. Boston, Allyn \& Bacon.

DECC (2011). Digest of United Kingdom Energy Statistics. DECC. London.

Druckman, A., M. Chitnis, et al. (2011). Missing carbon reductions? Exploring rebound and backfire effects in UK households. Energy Policy 39 (6): 3572-3581.

Gill, Z., M. Tierney, et al. (2010). Low-energy dwellings: the contribution of behaviours to actual performance. Building Research \& Information 38(5): 491-508.
Jelsma, J. and M. Knot (2002). Designing environmentally efficient services; a 'script' approach. The Journal of Sustainable Product Design 2(3/4): 119-130.

Lilley, D. (2009). Design for sustainable behaviour: strategies and perceptions. Design Studies 30(6): 704-720.

Lindenberg, S. and L. Steg (2007). Normative, Gain and Hedonic Goal Frames Guiding Environmental Behavior. Journal of Social Issues 63(1): 117-137.

Martiskainen, M. and J. Coburn (2010). The role of information and communication technologies (ICTs) in household energy consumptionprospects for the UK. Energy Efficiency 4(2): 209-221.

Norman, D. (1990). The design of Everyday Things. New York, Double Day.

Phillips, R. and S. Rowley (2011). Bringing it home. Using behavioural insights to make green living policy work. Green Alliance, London.

Steg, L. and C. Vlek (2009). Encouraging proenvironmental behaviour: An integrative review and research agenda. Journal of Environmental Psychology 29(3): 309-317.

Stern, P. C. (1999). Information, incentives, and proenvironmental consumer behavior. Journal of Consumer Policy 22(4): 461-478.

Verplanken, B. and H. Aarts (1999). Habit, attitude, and planned behaviour: is habit an empty construct or an interesting case of goal-directed automaticity? European review of social psychology 10(1): 101-134.

Verplanken, B. and W. Wood (2006). Interventions to break and create consumer habits. Journal of Public Policy \& Marketing 25: 90-103.

Wilson, G., T. Bhamra, et al. (2010). Design for Sustainable Behaviour: Reducing Domestic Energy Consumption through User Centred Design. ERSCP-EMSU Conference. Delft, The Netherlands, October 25-29, 2010.

Zachrisson, J. and C. Boks (2010). When to Apply Different Design for Sustainible Behaviour Strategies? ERSCP-EMSU Conference, Delft, Netherlands. October 25-29, 2010 